\title{
M ovimento cultural nos estudos organizacionais: uma abordagem interdisciplinar focada no consumo e na globalização
}

\author{
Alexandre Faria*
}

Ana Guedes*

\section{Resumo}

Este artigo revê e analisa o movimento 'cultural' em estudos organizacionais (EO) iniciado nos anos de 1990 no Brasil sob uma abordagem focada em consumo e globalização. Por meio dessa abordagem interdisciplinar os autores mostram que (a) as áreas de organizações, estratégia e marketing têm uma raiz histórica comum - a legitimação das grandes empresas - que ficou mais problemática no contexto da globalização. Por isso é argumentado que pesquisadores de EO no Brasil deveriam reconhecer, ao invés de desprezar, a dimensão do consumo. Os autores argumentam que tanto o desprezo da área de EO pelo âmbito do consumo quanto o movimento cultural parecem ser explicados pela expansão da academia na área de administração no contexto da globalização e pelo interesse das grandes corporações de camuflar a crescente assimetria entre os âmbitos da produção e do consumo. No final os autores destacam algumas implicações dessa abordagem para a promoção de interdisciplinaridade e para a relevância local do conhecimento.

Palavras-chave.: estudos organizacionais ; consumo; globalização.

\section{Abstract}

This paper reviews and analyzes the "cultural" movement in organizational studies (OS), which began in Brazil in the 1990's under an approach that focused on consumption and globalization. What the authors are trying to tell through this interdisciplinary approach is that organizational, strategic and marketing areas have a common historical origin legitimation of big companies - that became more problematic in the context of globalization. For this reason, it is said that OS researchers in Brazil should recognize the consumption dimension, instead of suppressing it. The authors argue that the suppression of consumption dimension by the OS area as well as cultural movement seem to be explained by the expansion of the management academy and by the interest that big companies have in hiding the increasing asymmetry between the domains of production and consumption in the context of globalization. In the end, the authors point out some implications of this approach for the promotion of interdisciplinarity and the local relevance of knowledge.

Keywords: organizational studies; consumption; globalization.

\section{Introdução}

Historicamente, no Brasil, os acadêmicos da administração convivem com áreas e conhecimento produzidos e legitimados em outros países, notadamente nos EUA. Assim como diversos outros pesquisadores que não têm o poder de governar a "grande academia", mesmo nos EUA, temos reduzidas chances, no Brasil, de selecionar, de forma consciente, os paradigmas ou orientações que consumimos, e de refletirmos criticamente sobre como tais práticas de consumo influenciam aquilo que produzimos (JOHNSON e DUBERLEY, 2003).

Incomodados de alguma forma com esse quadro, acadêmicos brasileiros da área de estudos organizacionais constituíram em meados dos anos 1990, um movimento cujo principal propósito é desafiar a hegemonia, a importação e o consumo acrítico do conhecimento em administração produzido nos EUA (MOTTA e

\footnotetext{
"Professor da EBAPE. Ph.D em Administração de Empresas pela University of Warwick. E-mail: afaria@ fgv.br

" Professora da EBAPE. Ph.D. em Relações Internacionais, pela London School of Economics and Political Science. E-mail: guedes@ fgv.br. 
CALDAS, 1997; CALDAS e WOOD JR, 1997; MOTTA, ALCADIPANI e BRESLER, 2001; RODRIGUES e CARRIERI, 2001). Apesar de certa importância alcançada na área dos estudos organizacionais, esse movimento cultural ainda não atingiu as outras disciplinas da administração, nem conseguiu a esperada importância para organizações e sociedade locais.

Os autores deste artigo mostram que a esperada relevância desse movimento no Brasil pode ser alcançada se, para compreendê-lo e implementá-lo, adotarmos uma abordagem focada no consumo e na globalização. Considerando o avanço da globalização, a expansão do mercado global e a disseminação das estratégias globais, argumentamos que o movimento cultural sinaliza que acadêmicos no Brasil passaram a enfrentar, a partir dos anos 1990, problemas similares àqueles enfrentados pelos consumidores - principalmente nos países em desenvolvimento. A abordagem aqui desenvolvida deveria resultar em desenvolvimentos interdisciplinares no Brasil entre as áreas de estudos organizacionais, de marketing e de estratégia, bem como na produção de conhecimento acadêmico que seja relevante.

Esse artigo é composto por uma introdução e cinco seções. Na primeira seção, fazemos uma breve revisão do movimento cultural, recorrendo a uma abordagem centrada no consumo e na globalização. Na segunda, descrevemos como as áreas de estudos organizacionais, estratégia e marketing foram constituídas e por que pesquisadores de estudos organizacionais desprezam a dimensão do consumo. Na terceira, tentamos mostrar como e por que a dimensão do consumo pode ser tratada com uma abordagem organizacional e estratégica. Na quarta seção, enfatizamos os efeitos da globalização no nosso entendimento de tais questões e indagamos se as divisões disciplinares estabelecidas pela "grande academia" fazem sentido na realidade brasileira. Na última seção, apresentamos as principais conclusões e as implicações futuras para pesquisas no campo dos estudos organizacionais.

\section{Uma revisão do movimento "cultural" no Brasil}

As críticas feitas por pesquisadores de estudos organizacionais no Brasil à hegemonia do conhecimento produzido nos EUA não devem ser vistas como um movimento novo no país. Essas críticas mais recentes reproduzem contribuições de outros autores importantes, tais como Guerreiro Ramos (1981), Tenório (1997), Tragtenberg (1980), Motta (2001) e Paes de Paula (2001). Feita essa ressalva, argumentamos que o contexto dos anos 1990, em que emergiu o movimento cultural, tem particularidades que devem ser analisadas.

A constituição desse movimento cultural no Brasil da década de 1990 coincide com três fenômenos importantes:

a. a emergência da abordagem crítica em administração no Reino Unido (ALVESSON e WILLMOTT, 1992; 1996) como reação ao tipo dominante de conhecimento acadêmico nesse âmbito,

b. ampliação de movimentos locais contrários ao avanço da globalização, à expansão do mercado global e à proliferação das estratégias globais das grandes empresas (HARRISON, 2003; KLEIN, 2000; FRANK, 2002; ZOU e CAVUSGIL, 1996); e

c. emergência de argumentos dentro dos EUA contra o status quo da área de estudos organizacionais e em favor da produção de conhecimento menos paroquial e viesado (BOYACIGILLER e ADLER, 1991).

No Brasil, o movimento cultural pode ser interpretado como uma reação organizada, local e estratégica, no contexto da globalização, ao processo de "gerenciação" (ALVESSON e DEETZ, 2000) e "marketização" da sociedade (BROWNLIE et al, 1999) - abrangendo consumidores, trabalhadores, políticos, cidadãos e também acadêmicos -liderado pelos EUA. Em outras palavras, o movimento cultural tem a ver com a crescente assimetria entre as dimensões da produção e do consumo trazida pelo avanço da globalização, pela expansão do mercado global e pela proliferação das estratégias globais. Mais especificamente, esse movimento confirma que o processo de expansão dessa assimetria vem ocorrendo não somente no âmbito da empresa, mas também no âmbito da academia (PHILO e MILLER, 2001). 
O movimento cultural no Brasil se alinha com as críticas formuladas no eixo anglo-saxão por pesquisadores de diferentes áreas (ALVESSON, 1994; KNIGHTS e MORGAN, 1990; BOYACIGILLER e ADLER, 1991) e em países fora do eixo EUA-Europa (WALTERS, 2001; IBARRA-COLADO, 1996) contra a expansão da hegemonia americana. Conseqüentemente, o movimento ecoa questionamentos em relação à extraordinária expansão do "mercado" e da academia de administração nos últimos 15 anos (FRIGA, BETTIS e SULLIVAN, 2004). Mesmo seguindo perspectivas específicas, esses autores concordam em um ponto: os conhecimentos produzidos na área de administração são construções sociopolíticas que não podem ser "consumidas" de forma acrítica (CLEGG, 1990).

A despeito (ou exatamente por causa) da racionalidade positivista dominante no campo da administração, as disciplinas ou áreas não podem ser tidas como neutras ou isentas de valores (ARNDT, 1985; ALVESSON e WILLMOTT, 1996). Em grande parte, disciplinas ou áreas da administração e as atividades correspondentes de produção e difusão do conhecimento acadêmico são subordinadas a interesses e perspectivas dominantes.

A hegemonia dos EUA na área de administração - tanto no âmbito da organização empresarial quanto no da academia - já era preocupante antes dos anos 1990. Entretanto, até então, a influência e a disputa pela hegemonia não eram tão problemáticas, mesmo para os EUA. Essa histórica hegemonia americana se caracterizou pela marginalização do "outro" e pelo privilégio das dimensões da produção e da distribuição em detrimento da dimensão do consumo. Não é por acaso que conhecimento dominante nas áreas de marketing e estratégia assume as perspectivas do "capitão do canal" e das elites corporativas.

Marginalizados como outsiders e tratados (também por nós mesmos) como meros consumidores, fomos acostumados a consumir produtos e textos acadêmicos vindos dos EUA e a perceber fenômenos de estratégia e de marketing da perspectiva da corporação e de seus altos executivos (SHRIVASTAVA, 1986) e não pelo prisma "local" do gerente, do consumidor ou do cidadão.

Fomos acostumados a perceber problemas gerenciais ou acadêmicos no Brasil da perspectiva ditada pela "grande academia" que se construiu a partir dos EUA. Nos anos 1990, a globalização ampliou o mercado do conhecimento em administração e também amplificou tanto a área de influência quanto os impactos dessa hegemonia. Mais especificamente, a globalização catalisou a preocupação de outros pesquisadores (inclusive, dentro dos EUA) que se viram forçados a consumir certo tipo de conhecimento.

A globalização também fez com que abordagens críticas focadas no consumo e no mercado ganhassem ainda mais importância em países em desenvolvimento. Nesses países, o desequilíbrio estrutural entre grandes empresas e consumidores (ou entre a "grande academia" e pesquisadores) é historicamente muito mais acentuado do que em países desenvolvidos. No final das contas, o conhecimento acadêmico ajuda a reproduzir e constituir esse quadro de assimetria. Nesse sentido, analistas argumentam que "pessoas em sociedades menos economicamente eficientes, (países ex-comunistas e do Terceiro Mundo) têm inveja dos países capitalistas avançados, devido a sua riqueza econômica e capacidade de produzir e entregar os produtos" (ALVESSON, 1994, p.297). Em correspondência a esse processo, o conhecimento dominante nas áreas de estratégia e de marketing vem facilitando há décadas a entrada em mercados periféricos, tanto de empresas e de produtos vindos dos EUA quanto de idéias e práticas associadas aos conceitos de livre mercado e livre-empresa. No contexto da globalização, esse quadro de assimetria ficou ainda mais problemático e isso afetou consumidores de produtos e de conhecimento acadêmico.

A constituição do movimento cultural no Brasil da década de 1990 não pode ser explicada somente por tais forças e mecanismos. O movimento foi facilitado por duas características dos estudos organizacionais (em especial, fora dos EUA), a fragmentação e a interdisciplinaridade, que não são encontradas ou permitidas em áreas mais relacionadas à dimensão do consumo e ao mercado, tais como marketing e estratégia. Essas características dão mais chances ao consumidor de conhecimento em estudos organizacionais de se transformar em genuíno produtor de saber do que em outras áreas, ainda que influentes autores baseados nos EUA argumentem que tais características prejudiquem a captação de recursos para pesquisa e a constituição de uma base comum de conhecimento (PFEFFER, 1992). 
Essas características são praticamente inexistentes, ou muito tênues, em áreas do conhecimento em administração mais relacionadas à dimensão do consumo. Mais especificamente, fragmentação e interdisciplinaridade são possibilidades praticamente desconhecidas, em especial no Brasil, pela maioria dos pesquisadores das áreas de estratégia e marketing. Esse cenário acarreta dois problemas importantes:

a. dificulta reações locais ou movimentos "culturais" nessas (e a partir dessas) áreas do conhecimento, e

b. contribui para impedir que pesquisadores dos estudos organizacionais desafiem o conhecimento dominante produzido e consumido nas áreas de estratégia e de marketing.

Apesar dos diversos obstáculos políticos e acadêmicos no contexto das ciências sociais, para o desenvolvimento da interdisciplinaridade (KNIGHT e WILLMOTT, 1997), os estudos organizacionais permitem a seus pesquisadores explorarem outras áreas, tais como a sociologia, a antropologia ou a ciência política, para lidar com questões organizacionais importantes, como identidade, subjetividade e cultura. Apesar dos diversos obstáculos, a área vem conseguindo transferir o debate para outros segmentos administrativos, tais como a contabilidade e os recursos humanos. Assim, pesquisadores dos estudos organizacionais têm tido mais liberdade para exercer os papéis de "consumidor ativo" e de produtor.

As áreas de estratégia e de marketing, mais relacionadas ao consumo e ao mercado, continuam refratárias à interdisciplinaridade e à fragmentação. Isso ajuda a explicar por que essas são avaliadas como duas das mais controversas ou contestáveis áreas no âmbito da administração (ARNDT, 1985; ALVESSON, 1994; ALVESSON e WILLMOTT, 1996; SHRIVASTAVA, 1986). Em sua grande maioria, acadêmicos dessas áreas no Brasil continuam agindo como consumidores disciplinados do conhecimento produzido nos EUA.

Em conjunto, essas questões ajudam a explicar por que o movimento cultural iniciado no Brasil pela área de estudos organizacionais no início dos anos 1990 enfrenta dificuldades para influenciar as áreas de estratégia e de marketing. Apesar do desprezo da área de estudos organizacionais pelo consumo e pelo mercado, como também pelas dificuldades para influenciar essas outras áreas, entendemos que, em nome da relevância, essas questões sejam desafiadas por pesquisadores no Brasil. A compreensão de como as áreas de estudos organizacionais, estratégia e marketing se constituíram nos EUA pode ser útil para esse propósito.

\section{Origens dos estudos organizacionais, estratégia e marketing}

\section{A força da grande corporação nos EUA}

Desde um primeiro momento, o ambiente externo tem sido um dos domínios mais importantes para a constituição e a legitimação da área de estudos organizacionais na academia nos EUA. A construção do ambiente externo pela literatura daquele país como um domínio ameaçador à sobrevivência legitima, sob uma abordagem particular, a existência e a permanência da organização: "para sobreviver, a organização se 'adapta' ao ambiente externo" (KNIGHTS e MORGAN, 1993, p.213).

Quando se constituiu em meados da década de 1960, nos EUA, a área de estratégia praticamente passou a monopolizar o entendimento e a análise do ambiente externo. Aproveitando a ênfase dada pela área de estudos organizacionais, a área de estratégia construiu a idéia de que seu princípio fundamental é a adaptação da empresa ao ambiente externo. Apesar da área de estratégia representar desde o início a grande empresa, essa idéia foi facilmente consumida por acadêmicos porque, em geral, organizações são representadas pela área de estudos organizacionais como "structure-takers, not structure-makers" (CLEGG, 1990, p.81). Não surpreende que até hoje "diversos professores de estratégia e política de negócios ainda focam em estratégia como o processo de desenvolver o ajuste entre a organização e seu ambiente externo" (SPENDER, 2001, p.27). De certa maneira, podemos argumentar que essas características refletem não somente a influência da área de estratégia sobre a de estudos organizacionais, como também a influência hegemônica da grande corporação na constituição dessas áreas nos EUA.

De modo diferente ao da Europa, onde o etos das universidades era separado do da indústria e do mundo do trabalho, nos EUA, industriais importantes e poderosos - como Carnegie, Mellon, Sloan e outros - 
apoiaram instituições, no mais elevado status possível dentro do sistema universitário americano, com o propósito declarado de encorajar a pesquisa e o treinamento no campo de negócios (KNIGHTS e MORGAN, 1991, p.256).

Por sua vez, a área de marketing praticamente detém o monopólio do mercado, que é uma das mais importantes representações do chamado ambiente externo. Diversos autores da área de marketing argumentam, e se vangloriam disso, que o foco no ambiente externo é o principal elemento por trás da histórica aproximação entre marketing e estratégia.

Entretanto, existe outra interpretação menos ingênua a respeito dessa aproximação. A área de estratégia, e em particular a de estratégia corporativa, está íntima e historicamente relacionada ao âmbito militar e às práticas e à ideologia correspondentes. Segundo autores vindos da área de sociologia, "trata-se de uma atividade conduzida pela elite militar, em que a massa de soldados se sujeita a sacrifícios; se necessário, em busca do objetivo de longo prazo" (KNIGHTS e MORGAN, 1990, p.477). De modo correspondente, na grande empresa e na academia de administração, essa bagagem sustenta o clássico princípio de que a "estrutura segue a estratégia" e a distinção hierárquica entre a estratégia e as áreas funcionais. Cabe então relembrar como a área de estratégia surgiu nos EUA.

Desde as primeiras décadas do século passado, havia interesse nos EUA de se desafiar a filosofia do livremercado e a idéia da "mão invisível" para que fossem criadas condições de se constituir e legitimar a filosofia da livre empresa (em outras palavras, da grande empresa) e a idéia da "mão visível". Por isso, era preciso transformar o mercado num domínio que elevasse e legitimasse, de certa maneira - ou seja, mantendo a organização como structure-taker -, as intenções, ações e capacitações do "estrategista" da grande empresa e, paralelamente, a grande empresa junto à sociedade local e às de outros países.

A construção da idéia de que havia um mercado constituído por consumidores soberanos, que tinham necessidades e desejos complexos e que detinham considerável poder para governar as atividades da produção, representava uma das mais importantes estratégias das grandes empresas, na época, para suprimir o Estado e as políticas de regulação correspondentes. Para reforçar a construção da idéia de que grandes empresas não eram suficientemente poderosas (ou structure-makers) para manipular o mercado nos EUA ou em outros países, a área de estratégia descrevia o ambiente externo como muito mais amplo e complexo (BOURGEOIS, 1980) do que o "mercado de consumidores".

Na verdade, a aproximação entre as áreas de estratégia e de estudos organizacionais e entre as de estratégia e de marketing refletem um problemático processo de disputas político-econômicas verificadas tanto nas organizações quanto na academia. Em termos históricos, a estratégia das corporações costuma ser a de procurar reduzir a competição e ter maior controle político e econômico dos chamados 'mercados' (WHITTINGTON, 2001; AKTOUF, 2002; SCHENDEL et al, 1980). Mais recentemente, autores favoráveis ao avanço da globalização e à expansão da corporação global sugeriram que a destruição do bem-estar social não é meramente um subproduto eventual da estratégia das grandes corporações globais, mas sim seu objetivo fundamental, visto que a estratégia global tem tido como principal foco evitar a livre competição (GHOSHAL et al, 1999).

Por essa razão, mesmo no contexto da globalização, no qual as corporações globais têm mais poder do que diversos constituintes do mercado (incluindo o Estado), análises na área de estratégia oscilam entre o voluntarismo - caracterizado pelas elevadas intenções do estrategista da grande empresa - e o determinismo estrutural, no qual a "estratégia é vista simplesmente como um produto das forças do mercado" (KNIGHTS e MORGAN, 1990, p.476).

No Brasil, pela influência do formalismo com um dos traços culturais locais mais importantes, sabemos, como cidadãos, agentes sociohistóricos e consumidores ativos, que evitar a livre competição é o foco principal da estratégia dessas grandes corporações. Entretanto, como acadêmicos, temos dificuldades de perceber a grande empresa dessa maneira porque, antes de produzirmos qualquer tipo de conhecimento, fomos acostumados a cumprir o papel de consumidores disciplinados do conhecimento produzido nos EUA. 
Segundo diversos autores, a função do marketing nas grandes corporações é, principalmente, manipular os desejos e as necessidades tanto de consumidores individuais quanto de coletividades mais amplas (MORGAN, 1992). Reproduzindo o direcionamento das estratégias corporativas, as estratégicas de marketing - tratadas por alguns como a parte visível da estratégia empresarial (ROCHA e CHRISTENSEN, 1999) - costumam ter como foco principal a dimensão política ou "invisível" dos mercados, visando controlá-los (HUTT, MOKWA e SHAPIRO, 1986) ou domesticá-los (ARNDT, 1979).

Porém, tendo em vista nosso papel de consumidores disciplinados do conhecimento acadêmico produzido pela "grande academia" americana, enfrentamos dificuldades para perceber o marketing e as estratégias correspondentes das grandes corporações por meio dessas outras abordagens.

Essas características não têm a ver tão e somente com a predominância do conhecimento produzido pela "grande academia" dos EUA. Na verdade, essas características refletem a influência político-econômica da grande empresa americana sobre o mercado, desde o início do século passado, e também sobre os processos de constituição e legitimação da academia de administração e de suas disciplinas (LOCKE, 1996).

Construída nos EUA, a abordagem dominante se baseia no argumento de que às pequenas empresas restaria somente esperar por uma certa representação da mão invisível - a de "destino" ou "desígnio divino". As grandes empresas, embasadas no imaginário do cowboy e do individualismo americano (O'SHAUGHNESSY, 1985), é que seriam os agentes capazes de controlar as forças desse mercado, por meio do planejamento racional e de estratégias adequadas. De outro modo, essas empresas - tidas como qualquer outro tipo de organização - não sobreviveriam e não produziriam o esperado bem-estar social.

Os problemas advindos dessa histórica influência da grande corporação, os quais vêm se intensificando nos últimos anos devido ao avanço da globalização, ajudam a explicar por que surgiu no Brasil, nos anos 1990, o movimento cultural em reação à hegemonia anglo-saxônica.

O poder relativo da área de estratégia explica em grande parte a histórica busca da área de marketing por um status estratégico (DAY e WENSLEY, 1983). Essas características igualmente ajudam a explicar o poder colonizador da área de estratégia em relação às áreas de estudos organizacionais e de marketing (ALVESSON e WILLMOTT, 1996; WHITTINGTON, 2001).

\section{0 afastamento dos estudos organizacionais da dimensão do consumo}

Com a abordagem desenvolvida neste artigo podemos tentar compreender como e por que a dinâmica entre as áreas de estratégia e de marketing tem a ver com o afastamento dos estudos organizacionais da dimensão do consumo. A análise genealógica feita por Knights e Morgan (1991) sobre as condições históricas que permitiram o surgimento do discurso da estratégia corporativa nos EUA e da área de estratégia na academia de administração é de central importância.

Knights e Morgan (1991) argumentam que até os anos 1930, a academia era dominada por debates centrados no taylorismo. Foi então, que começaram as discussões (lideradas por Mayo) centradas na psicologia industrial. A principal preocupação nesses debates era com o controle da produção e do trabalho na grande empresa. Isso explica a instalação gradual de sistemas e mecanismos de controle dentro da organização, verificada até a II Guerra Mundial.

Após o conflito, emergiram discursos e mecanismos voltados para o controle do que estava "fora" da organização. Esses discursos e mecanismos - apropriados e liderados pelas áreas de estratégia e de marketing acabaram reproduzindo e reforçando uma ideologia de âmbito intra-organizacional que remete à década de 1930. Em outras palavras, a idéia de que as forças do mercado podem ser controladas pelos mecanismos de planejamento "era em grande parte um desenvolvimento lógico da idéia de que pessoas podem ser controladas e monitoradas" (KNIGHTS e MORGAN, 1991, p.259). Tal argumentação demonstra que o distanciamento entre os estudos organizacionais e as áreas de estratégia e marketing (assim como as distinções feitas entre "ambiente interno" e "ambiente externo") é tácita e ilusória. 
O ainda grande número de pequenas firmas nos EUA naquela época era governado pela idéia de "mão invisível". Ou seja, o mercado não era tido como um domínio a ser controlado pela firma ou pelo estrategista. A divisão do mercado entre essas firmas e os conglomerados formados por industriais poderosos como Rockfeller, Morgan e Carnegie, a partir dos anos 1940, começaram a desafiar essas representações de mercado ou ambiente externo. Após a II Guerra - seja pelo extraordinário crescimento dos conglomerados industriais americanos, pelos problemas de controle enfrentados por esses conglomerados por atuarem em diversos países e regiões, pela constituição das formas multidivisionais de organização e devido à crescente competição em nível de produtos - surgiram práticas e conceitos de estratégia e de marketing baseados no argumento de que a grande empresa deveria se dedicar a "controlar o que estava fora da organização" (KNIGHTS e MORGAN, 1991, p.2590).

Tendo em vista a hegemonia dos EUA após a II Guerra, a divisão de responsabilidades entre as áreas que se estabeleceu na "grande academia" se reproduziu em diversos outros países. Assim como nos EUA, acadêmicos dos estudos organizacionais no Brasil praticamente não problematizam o ambiente externo ou o mercado, enquanto acadêmicos das áreas de estratégia e de marketing geralmente não problematizam a organização. Assim, as construções dominantes sobre mercado e o ambiente externo ajudaram a legitimar as grandes empresas e também as áreas de estudos organizacionais, estratégia e marketing.

A partir do início dos anos 1990, essa divisão entre áreas se fortaleceu devido à noção de que a globalização tornava o mercado e o ambiente externo ainda mais complexos e ameaçadores. $\mathrm{O}$ ambiente externo passou a ser tratado pela maioria dos acadêmicos das áreas de estratégia e de marketing dos EUA como mercado global. Por sua vez, a extrema complexidade atribuída ao mercado global seria causada pela dissolução de fronteiras nacionais e pela possibilidade de se atingir qualquer consumidor e o entorno de qualquer organização. Em outras palavras, segundo a literatura dominante produzida nos EUA e consumida em todo o mundo, o mercado global atinge e altera toda e qualquer tentativa da empresa para controlar o ambiente externo (GER, 1999), esteja essa empresa sediada em países desenvolvidos ou em desenvolvimento (CRAIG e DOUGLAS, 1996), independentemente de seu porte ou nível de poder político e econômico. Dessa forma, as corporações globais foram tidas como structure-takers, e as estratégias globais ganharam legitimidade e força no contexto acadêmico de diversos países, apesar do argumento de que tais estratégias são imperialistas (KORTEN, 2001).

O movimento cultural no Brasil teve que desafiar não somente esse cenário, mas também certas influências teóricas. Pesquisadores brasileiros que baseiam seus trabalhos nas versões mais conhecidas da teoria institucional costumam argumentar que o chamado ambiente externo não deve ser visto da perspectiva "técnica" tradicional, segundo a qual as organizações almejam unicamente a eficiência. Eles argumentam que o ambiente deve ser compreendido e analisado de uma perspectiva institucional que privilegie questões de legitimação e sobrevivência. Na observação dos ambientes institucionais das organizações chama a atenção as pressões sociais para que elas se amoldem a formas locais de racionalidade (MEYER e ROWAN, 1977; DiMAGGIO e POWELL, 1983). Dessa perspectiva, normas sociais forçam organizações a adotarem procedimentos tidos como racionais, para que sejam percebidas como legítimas e possam ampliar suas chances de sobrevivência. Grandes empresas podem então ser representadas como entidades com pouco poder político e econômico, tendo em vista essa extraordinária gama de pressões externas. Essa bagagem torna mais difícil o reconhecimento de que grandes empresas têm poder para construir ou legitimar conceitos e instituições e também moldar a sociedade ou o mercado.

O resultado é conveniente não somente para grandes corporações, mas também para os gatekeepers das correspondentes áreas do conhecimento acadêmico que compõem a "grande academia". Quanto mais complexa é a representação do ambiente externo ou do mercado, mais relevante fica a organização. Por conseguinte, mais importante fica a área de estudos organizacionais. O mesmo raciocínio se aplica ao ambiente externo, à área de estratégia e, finalmente, ao mercado e ao marketing.

Contudo, o afastamento dos estudos organizacionais da dimensão do consumo tem de ser questionado recorrendo-se a uma abordagem focada no consumo, que enfatize a crescente assimetria entre produção e consumo e desafie a ideologia de que grandes empresas são structure-takers. Em conseqüência do avanço da globalização, esse afastamento em países em desenvolvimento é extremamente problemático, a despeito das 
regras estabelecidas pela "grande academia". Diversos analistas (FONTENELLE, 2002; FRANK, 2002; SKLAIR, 2002; KLEIN, 2002) vêm ressaltando que o consumidor (visto também como cidadão e trabalhador) é o que menos se beneficia do avanço da globalização, da expansão do mercado global e da proliferação das estratégias globais, principalmente, em países em desenvolvimento. Esse cenário ajuda a explicar a emergência e o fortalecimento de organizações formadas a partir da dimensão do consumo - tal como as organizações voltadas para a proteção do consumidor e as agências regulatórias de setores importantes - e também o próprio movimento cultural no Brasil.

\section{Reconhecendo a organização via consumo}

A seção anterior mostrou por que não é fácil para os estudos organizacionais terem o consumo e as organizações correspondentes como foco central. Pesquisadores da área enfrentam obstáculos para reconhecer as organizações que emergem do mercado de consumo e que se opõem ao mercado de produção liderado pelas grandes empresas. Merecem nosso entendimento alguns obstáculos. Nesse sentido, a abordagem teórica dominante na área de estratégia, apoiada pela representação de structure takers, nos mostra o ambiente externo como um domínio amorfo que deve ser controlado ou dominado pela grande empresa. Assim como na área de estudos organizacionais, a perspectiva privilegiada é a da produção, em detrimento da do consumo.

$\mathrm{Na}$ área de estratégia, a construção da idéia de que a competição dessas empresas pelo mercado de consumidores, ao invés da planificação do mercado pelo Estado, traria progresso e bem-estar social para o país foi de central importância para evitar reações quanto à crescente assimetria de poder entre as grandes empresas e os consumidores individuais e, correspondentemente, quanto aos abusos cometidos por essas empresas em relação a estes ou a qualquer outra instância da sociedade.

A abordagem teórica dominante na área de marketing, também construída nos EUA, revela o mercado como um contexto sem forma definida composto por consumidores individuais que se comportam segundo racionalidades específicas. A construção da idéia de que a diversidade do mercado de consumo significava a liberdade de escolha dos indivíduos era importante para evitar a noção de que a planificação do mercado de produção pelo Estado seria mais eficaz. A literatura de marketing reproduz a filosofia de que somente a "empresa livre", em regime de competição pelo mercado de consumidores, poderia produzir o necessário bemestar para a sociedade.

Grupos de consumidores do mundo "lá fora" são tratados pelas disciplinas de marketing e de estratégia como mercados ou segmentos de mercado, os quais devem ser conquistados. Nos textos que consumimos, grupos no mercado não são, por conseguinte, tratados como organizações. As organizações do mercado que reagem ao poder e aos eventuais abusos das grandes empresas por meio de estratégias específicas são desprezadas pelos periódicos acadêmicos mais reputados na área de marketing (rara exceção é SMITH, 1987). A supressão de debates sobre os antecedentes e as implicações sociopolíticas da área de marketing pela "grande academia", e mais especificamente sobre os constituintes que governam ou deveriam governar o mercado, se fortaleceu nos anos 1990 devido ao avanço da globalização. Em grande parte isso se explica pelo interesse das grandes corporações de que esse tipo de questionamento não faça parte da agenda acadêmica de pesquisas que elas mesmas ajudam a financiar (WILKIE e MOORE, 2003; ANDREASEN, 1997).

Os autores deste artigo propõem então que o mercado de consumo seja abordado pela área de estudos organizacionais no Brasil também como um conjunto de organizações que resistem estrategicamente ao crescente poder e aos eventuais abusos das grandes corporações. Isso implica o reconhecimento de que o movimento cultural brasileiro deve ser compreendido e analisado como uma organização de consumo no âmbito da academia.

Um dos exemplos mais importantes para embasar essa proposta é o da expansão e o do fortalecimento recente, nos mais diversos países e em particular no Brasil, de organizações dedicadas à defesa do consumidor (GUEST, 2002). Essas organizações vêm se expandindo no âmbito global e o fenômeno deve ser entendido como uma forma de resistência a certas práticas estratégicas ou de marketing implementadas pelas corporações 
globais e também por grandes empresas locais. Esse fenômeno ajuda a explicar a crescente preocupação de pesquisadores das áreas de estratégia e marketing com ética, responsabilidade social e políticas públicas (BLOOM, 1997).

Por um lado, reações organizadas locais vêm sendo observadas em diferentes países. Por outro, tem crescido o número, a diversidade e o alcance de empresas que enganam, iludem ou dão prejuízo ao consumidor/cidadão (FELCHER, 2001; KNIGHTS, STURDY e MORGAN, 1994). A globalização - assim como a correspondente expansão dos domínios do 'livre mercado' e do raio de ação e influência da "livre empresa" - tem sido apontada por autores de diferentes países e áreas do conhecimento como a principal causa desse cenário de disputas (LYSONSKI, DURVASULA e WATSON, 2003; SKLAIR, 2002; KLEIN, 2002) que ainda não recebeu a devida atenção por parte da academia de administração.

A globalização está intimamente relacionada com o interesse das grandes empresas em padronizar o consumo nos mais diversos países ou regiões, expandindo o chamado mercado global. Esse processo assimétrico tem sido liderado por corporações transnacionais que não devem ser confundidas com instituições de caridade (SKLAIR, 1995) e que têm conquistado cada vez mais poder político-econômico desde o final dos anos 1980, em decorrência do enfraquecimento do Estado e das políticas públicas.

Tendo em vista esse cenário, a preocupação com a dimensão do consumo finalmente chegou aos estudos organizacionais nos EUA. Incomodados com práticas controversas das grandes empresas e com a abordagem dominante na área de marketing, que trata o consumidor como um mero meio para os fins da organização (BAZERMAN, 2000), alguns autores americanos defenderam nas páginas da Academy of Management Review, uma radical mudança de foco.

Criar valor real para o consumidor e, portanto, adicionar valor para a sociedade é um dos caminhos mais óbvios para as organizações fazerem do mundo um lugar melhor. Entretanto, nosso campo [o dos estudos organizacionais] tem ignorado quase completamente esse tópico! (BRIEF e BAZERMAN, 2003, p.187).

O que justifica essa aproximação interdisciplinar é que a globalização vem acentuando a assimetria entre as grandes corporações e os consumidores individuais, principalmente, em países menos desenvolvidos. Cabe aqui destacar que nos diferentes momentos históricos em que se observou uma incomum concentração de poder nas mãos das grandes organizações (principalmente empresariais), o mercado de consumidores individuais esteve em perigo (TIEMSTRA, 1992), provocando correspondentes reações em termos de organização desses consumidores. Nesses momentos, consumidores costumam se organizar para enfrentar o poder e a legitimidade das organizações empresariais.

Em outras palavras, não obstante tantos preconceitos e confusões criados em torno do conceito, o surgimento do consumerismo nos EUA não advém de um comprometimento profundo daquela sociedade com algum tipo de ética hedonista de consumo. Tampouco advém da preocupação abstrata com a "soberania do consumidor". De fato, se origina de uma "histórica e especificamente suspeita nos EUA quanto às grandes e poderosas instituições, em termos econômicos ou políticos" (TIEMSTRA, 1992, p.3).

De acordo com autores da sociologia global (SKLAIR, 2002, p.115), as corporações transnacionais vêm agindo no contexto da globalização como transmissores de uma certa cultura e ideologia capaz de manipular as necessidades de consumo. Em países em desenvolvimento, esse fenômeno, chamado de consumerismo global, resulta em padrões socioculturais de consumo capazes de bloquear o desenvolvimento local. Esse fenômeno também pode resultar em reações locais, similarmente à constituição do movimento cultural brasileiro na área de estudos organizacionais.

No Brasil, merece destaque o Instituto Brasileiro de Defesa do Consumidor (Idec), organização nãogovernamental de consumidores, sem fins lucrativos e sem qualquer vínculo com empresas, governos ou partidos político. Fundada em 1987, o Idec conseguir em poucos anos quase o mesmo impacto parecido que o alcançado pelo Consumers Union dos EUA a partir dos anos 1930. A coordenadora executiva do Idec, 
Marilena Lazzarini, preside desde o final de 2003 a Consumers International, que reúne mais de 250 associações de consumidores em mais de uma centena de países, e que se dedica à defesa dos consumidores, em especial, dos marginalizados, pobres ou em desvantagem. O impacto causado pela atuação do Idec - ainda que não venha recebendo a devida atenção por pesquisadores dos estudos organizacionais, de estratégia e de marketing no Brasil - reflete não somente uma reação às assimetrias trazidas pela globalização, mas também o fato do Brasil ser um mercado no qual os direitos dos consumidores são extremamente negligenciados.

Em diferentes épocas da história recente dos EUA, nas ocasiões em que se verificou o excessivo controle do mercado pelas grandes corporações, observou-se em seguida o declínio da legitimidade das instituições empresariais e, consequientemente, a emergência de mecanismos e "esforços para controlar esse poder" (TIEMSTRA, 1992, p.6). Uma das principais características da globalização tem sido a concentração de poder econômico e político nas mãos das grandes corporações. Reações vêm sendo verificadas em diferentes partes do mundo, representado risco real de perda de legitimidade social por essas corporações; fato que ajuda a explicar a crescente importância atribuída pelas grandes corporações à responsabilidade social.

Para neutralizar essa movimentos de reação, essas grandes corporações vem buscando sua legitimação através da expansão global da "grande academia". Nesse aspecto, os autores deste artigo argumentam que isso ajuda a explicar tanto a constituição do movimento cultural no Brasil quanto sua relevância potencial para a sociedade.

\section{Uma revisão crítica da globalização}

O termo globalização começou a ser efetivamente usado a partir do início dos anos 1970 (HELD e McGREW, 2000, p.7). Até então, as abordagens teóricas seguiam uma perspectiva de ortodoxia e pressupunham a separação entre questões internas e externas - mais especificamente entre os domínios nacional e internacional. A interdependência política e econômica era explicada principalmente por teorias rivais tais como a do sistema mundial e (WALLERSTEIN, 1974) e a da interdependência complexa (KEOHANE e NYE, 1977).

Mais recentemente, após a queda do chamado socialismo de Estado e o estabelecimento de uma certa versão do capitalismo como regime hegemônico em nível mundial, a globalização se transformou num conceito de central importância dentro da academia e de diversos domínios da vida pública ou privada. Apesar da importância, uma característica central da globalização é que poucos são capazes de defini-la com precisão.

Held e McGrew (2000, p.11) afirmam que não há, de fato, uma definição universalmente aceita para globalização (THOMPSON, 2000). Entretanto, a maior parte da literatura na área administrativaparticularmente nas áreas de estratégia e de marketing - reproduz, de forma consciente ou não, uma teoria específica quanto ao que seja globalização. É possível afirmar que essa teoria é a preferida pela "grande academia" porque reproduz e sustenta o processo de consolidação da hegemonia americana nas mais diversas frentes.

Mais especificamente, diversos autores influentes reproduzem uma abordagem teórica extrema da globalização, o chamado globalismo. Referindo-se a corporações transnacionais baseadas em países desenvolvidos, costumam afirmar que indústrias e empresas estão compelidas a "gerenciar seus negócios de uma forma mais integrada em termos globais, para alcançar os benefícios da eficiência" (BARTLETT e GHOSHAL, 1989, p.67). Eles acreditam que gerentes e executivos cumprem um papel mais ativo, pensando em termos globais e não em termos locais ou domésticos (OHMAE, 1989a).

Um problema que merece destaque é que a literatura sobre a globalização vem sendo marcada pela dominância de dois extremos teóricos. Segundo Held e McGrew (2000), dois grupos extremos ou "facções" dominam a literatura:

a. os que consideram a globalização um acontecimento histórico real e extremamente significativo - os chamados globalistas - e 
b. aqueles que concebem a globalização como construção ideológica ou mítica de valor explicativo marginal - os chamados céticos.

Os céticos afirmam que a globalização é um mito que serve para legitimar o projeto global neoliberal, cuja principal base conceitual ou ideológica é o chamado Consenso de Washington. Um ponto central na argumentação desses autores é o de que o chamado global não pode ser empiricamente investigado, e por isso o conceito não tem valor descritivo ou explicativo. Esses autores argumentam que as análises encontradas na literatura costumam se basear em modelos abstratos da economia global, da cultura global e da sociedade global. Os céticos defendem que um conceito mais válido seria internacionalização, regionalização ou "triadização" (HELD e McGREW, 2000, p.14-17).

Para pesquisadores de administração, o modelo defendido pelos céticos implica o reconhecimento da importância das fronteiras nacionais - o qual remete a perspectivas conceituais baseadas em imperialismo ou colonialismo - e nos aspectos políticos, econômicos, sociais e legais correspondentes. Essa proposta não é seguida pela literatura dominante na administração, porque seu foco no "nacional" contraria o foco no "internacional" e também os interesses das empresas transnacionais de evitar a emergência de qualquer tipo de "nacionalismo". Cabe destacar que o movimento cultural no Brasil pode, de certa maneira, ser também compreendido como um tipo de nacionalismo.

Além disso, a proposta dos céticos enfatiza questões políticas, especificamente o âmbito público e o governo, em vez de enfatizar questões econômicas, o âmbito privado e as grandes empresas. Essas características não se alinham com o direcionamento seguido pelas áreas de estratégia e de marketing. Tampouco contribuem para reforçar a posição de organizações como structure-takers, observada na área de estudos organizacionais.

A abordagem globalista refuta o argumento de que a globalização é uma construção ideológica ou um sinônimo de imperialismo ou neocolonialismo. Seus autores argumentam que há evidências concretas de que estão ocorrendo transformações estruturais reais no âmbito da sociedade e das organizações, causadas principalmente pela:

a. expansão das empresas multinacionais e do mercado de capitais,

b. difusão da cultura popular; e

c. crescente preocupação como a degradação ambiental do planeta.

Esses autores argumentam que a globalização não é um fenômeno exclusivamente econômico. Defendem uma perspectiva multidimensional que leva em conta as diversas redes de poder nos domínios econômico, político, cultural e tecnológico. De modo bastante particular, questionam a idéia de que tais domínios possam ser abordados de uma perspectiva universalista (HELD e McGREW, 2000, p.18-20).

Contudo, no final, eles reproduzem o discurso a favor da "livre empresa", ao enfatizarem que o domínio econômico é mais importante. Para isso, muitos dos autores argumentam que no contexto da globalização é o poder do consumidor que explica essa predominância. O poder do consumidor é tratado como a principal força por trás da consolidação da realidade transnacional.

Gerenciar de forma efetiva nesse novo ambiente sem fronteiras não significa construir pirâmides de fluxos de caixa por meio da descoberta de novos locais para investir. Tampouco significa perseguir seus concorrentes até o limite externo e derrotá-los em seu próprio mercado doméstico. Tampouco significa tentar reproduzir cegamente sistemas domésticos de negócios em novos territórios coloniais. Ao contrário, significa prestar particular atenção no propósito de entregar valor para os consumidores, e desenvolver uma visão eqüidistante de quem eles são e o que eles querem. Antes de tudo vem a necessidade de se ver claramente seus clientes. Eles - e não somente eles - podem fornecer razões legítimas para pensar globalmente (OHMAE, 1989a). 
Analistas das relações internacionais classificam esses autores como hiperglobalistas, por que estes acreditam num mundo sem fronteiras nacionais e na erosão do poder dos governos de gerir a economia nacional (HELD et al, 1999, p.281). No final das contas, o consumidor ocuparia essa lacuna de poder.

Na caixa registradora, você não se importa com o país de origem ou o país de residência. Você não pensa em índices de desemprego ou na balança de pagamentos. Você não se importa com onde o produto foi feito. [...] Tudo o que importa é a qualidade do produto, o preço, o design, o valor e o apelo para você como cliente (OHMAE, 1989b).

Apesar de não haver uma definição única de estratégia global (ZOU e CAVUSGIL, 1996), a literatura reproduz o discurso dos globalistas. Em um artigo influente nas áreas de marketing e de estratégia, Levitt (1983) argumentou que os avanços em tecnologias de comunicação e de transporte e o número crescente de viagens internacionais levariam à homogeneização dos mercados. Essa argumentação é central no conceito dominante de mercado global. Consumidores em diferentes partes do mundo tendem a dividir as mesmas preferências e a demandar os mesmos produtos.

De acordo com essa abordagem, as corporações multinacionais que tratam os mercados de países de forma separada deverão desaparecer e serem substituídas por corporações globais que vendem produtos padronizados da mesma maneira em todo o mundo. Uma principal fonte de vantagem competitiva passou a ser a capacidade de produzir produtos de alta qualidade a custos baixos, visto que consumidores globais sacrificariam suas preferências idiossincráticas por produtos de alta qualidade e baixo preço.

Levitt argumentou que a melhor estratégia global consiste em produzir um só produto padronizado e vendê-lo por meio de um programa padronizado de marketing. Autores importantes da área de estratégia (HAMEL e PRAHALAD, 1985) afirmam que uma ótima estratégia global exige variedade de produtos, para que investimentos em tecnologias, marcas e canais de distribuição possam ser compartilhados. Esses argumentos, que reproduzem a chamada orientação para produção ou para vendas, e não exatamente à orientação para marketing (PIERCY, 2002), refletem a crescente assimetria entre as dimensões da produção e do consumo, no contexto da globalização.

Baseados nos conceitos de competência essencial (PRAHALAD e HAMEL, 1990) e estratégia essencial (YIP, 2000) importantes autores afirmam que o imperativo estratégico global consiste em buscar formas de se subsidiar custos e investimentos, através das diversas linhas de produtos e mercados, da dominação de uma marca mundial e dos sistemas mundiais de distribuição.

Ghoshal, Bartlett e Moran (1999, p.10) vão um pouco além e afirmam que as sociedades modernas não são economias de mercado, pois segundo eles, as sociedades modernas são economias organizacionais nas quais as grandes empresas são os atores principais da criação de valor e no alcance do progresso econômico. Dessa perspectiva, o crescimento das empresas e, portanto, das economias depende fundamentalmente da qualidade de sua gerência (gestão).

\section{Considerações finais}

Este artigo demonstra que a adoção de uma abordagem centrada no consumo e na globalização pode nos ajudar a compreender melhor a constituição e a relevância da abordagem cultural constituída por pesquisadores de estudos organizacionais no Brasil, na década passada. $\mathrm{O}$ artigo também demonstra que o desenvolvimento desse tipo de abordagem requer que pesquisadores dessa área desafiem

a. o contexto sociopolítico em que as áreas de estratégia e de marketing se constituíram e se legitimaram nos EUA a partir do século passado; e

b. o preconceito de nos vermos cumprindo mais o papel de consumidores do que de produtores de conhecimento. 
Este artigo sugere que a divisão de responsabilidades entre as áreas construídas pela "grande academia" nos EUA e as aproximações das áreas de estratégia e marketing e das de estratégia e estudos organizacionais merecem ser revistas de uma perspectiva crítica no Brasil. Esse tipo de revisão pode ser útil para quatro importantes propósitos:

a. permitir uma melhor compreensão do movimento cultural constituído por pesquisadores de estudos organizacionais no Brasil na década de 1990;

b. ajudar a consolidar a relevância desse movimento cultural;

c. desmistificar a hegemonia da representação das grandes empresas como structure-takers no campo dos estudos organizacionais; e

d. motivar pesquisadores a um diálogo interdisciplinar mais franco dentro da academia da administração e entre a academia e a sociedade.

$\mathrm{O}$ texto ainda sustenta que o campo dos estudos organizacionais e as áreas de marketing e de estratégia têm uma mesma raiz histórica que merece ser criticamente revista no Brasil: a legitimação das grandes empresas. Através de uma revisão crítica da globalização e de seu significado dominante, os autores concluem que o desprezo do campo dos estudos organizacionais pelo âmbito do consumo parece ser governado pelos mesmos interesses históricos e, em particular, pelo interesse de se camuflar ou legitimar a crescente assimetria entre produção e consumo no atual contexto de globalização.

Finalmente, argumentamos que o movimento cultural constituído por pesquisadores de estudos organizacionais no Brasil na década passada é um importante ativo, e exemplo para a promoção de conhecimento que valorize a organização dos consumidores (de bens, serviços ou conhecimento acadêmico) quanto às forças assimétricas trazidas ou amplificadas pela globalização. 


\section{Referências bibliográficas}

AKTOUF, 0. Governança e pensamento estratégico: uma crítica a Michael Porter. Revista de Administração de Empresas, v.42, n.3, p.43$53,2002$.

ALVESSON, M. Critical theory and consumer marketing. Scandinavian Journal of Management, v.10, n.3, p.291-313, 1994.

ALVESSON, M.; DEETZ, S. Doing Critical Management Research. London: Sage, 2000.

ALVESSON, M.; WILLM OTT, H. Critical Management Studies. London: Sage, 1992.

Making sense of management. London: Sage, 1996.

ANDREASEN, A. From ghetto marketing to social marketing: bringing social relevance to mainstream marketing. Journal of Public Policy \& Marketing, v.16, n.1, p.129-131, 1997.

ARNDT, J. Toward a concept of domesticated markets. Journal of Marketing, n.43, p.69-75, 1979.

On making marketing science more scientific: the role of observations, paradigms, metaphors and puzzle solving. Journal of Marketing, n.49, p.11-23, 1985.

BARTLETT, G.; GHOSHAL, S. Managing Across Borders. London: Century, 1989.

BAZERM AN, M. Consumer research for consumers. Journal of Consumer Research, n.27, p.499-504, 2000.

BLOOM, P. Field of marketing and public policy: introduction and overview. Journal of Public Policy \& Marketing, v.16, n.1, p.126- 128, 1997.

BOURGEOIS, L. Strategy and environment: a conceptual integration. Academy of Management Review, v.5, n.1, p.25-39, 1980.

BOYACIGILLER, N.; ADLER, N. The Parochial Dinosaur: Organizational Science in a Global Context. Academy of Management Review, $v$. 16, n. 2, p.262-290, 1991.

BRIEF, A.; BAZERMAN, M. Editor's comments: bringing in consumers. Academy of Management Review, v.28, n.2, p.187-189, 2003.

BROWNLIE, D. et al (Ed.). Rethinking marketing. London: Sage, 1999.

CALDAS, M.; WOOD JR., T. 'For the English to see': the importation of managerial technology in late $20^{\text {th }}$ century Brazil. Organization, n.4, p.517-534, 1997.

CLEGG, S. Modern organizations. London: Sage, 1990.

; IBARRA- COLADO, E.; BUENO-RODRIGUEZ, L. Global management - universal theories and local realities. London: Sage, 1999.

CRAIG, C.; DOUGLAS, S. Developing strategies for global markets: an evolutionary perspective. Columbia Journal of World Business, v.31, n.1, 1996.

DAY, G.; WENSLEY, R. Marketing theory with a strategic orientation. Journal of Marketing, n.47, p.79-89, 1983.

DIM AGGIO, P.; POWELL, W. The iron cage revisited: institutional isomorphism and collective rationality in organizational fields. American Sociological Review, n.48, p.147-160, 1983.

FONTENELLE, I. 0 nome da marca: M CDonald's, fetichismo e cultura descartável. São Paulo: Boitempo, 2002.

FRANK, T. One market under God. London: Vintage, 2002.

FRIGA, P.; BETTSS, R.; SULLIVAN, R. Mudanças no ensino de administração: novas estratégias para o século XXI. Revista de Administração de Empresas, v.44, n.1, p.96-115, 2004.

GER, G. Localizing in the global village: local firms competing in global markets. California Management Review, v.41, n.4, p.64-83, 1999. GHOSHAL, S.; BARTLET, C.; MORAN, P. A. New manifesto for management. Sloan Management Review, p.9-20, spring 1999.

GUERREIRO RAMOS, A. The new science of organizations: a reconceptualization of the wealth of nations. Toronto: University of Toronto, 1981.

GUEST, J. Consumers and consumerism in America today. Journal of Consumer Affairs, v.36, n.2, p.139-149, 2002.

HAMEL, G.; PRAHALAD, C. Do you really have a global strategy? Harvard Business Review, v.67, p.139-148, July/Aug.1985.

HARRISON, R. Corporate social responsibility and the consumer movement. Consumer Policy Review, v.13, n.4, p.127-131, 2003.

HELD, D.; M CGREW, A. An introduction to the globalization debate. Cambridge: Polity Press, 2000.

HELD, D.; McGREW, A.; GOLDBLATT, D.; PERRATON, J. Global Transformations - Politics, Economics and Culture. London: Polity Press, 1999. 
HUTT, M.; MOKWA, M.; SHAPIRO, S. The politics of marketing: analyzing the parallel political marketplace. Journal of Marketing, n.50, p.40-51, 1986.

IBARRA-COLADO, E. Excellence at large: power, knowledge and organizational forms in Mexican universities. In: CLEGG, S.; PALMER, G. (Ed.). The politics of management knowledge. London: Sage, 1996.

JOHNSON, P.; DUBERLEY, J. Reflexivity on management research. Journal of Management Studies, v.40, n.5, p.1279-1303, 2003.

KEOHANE, R.; NYE, J. Power and interdependence: world politics in transition. Boston: Little Brown, 1977.

KLEIN, N. The tyranny of the brands. New Stateman, p.25-28, Jan. 24, 2000.

Sem logo: a tirania das marcas em um planeta vendido. Rio de Janeiro: Record, 2002.

KNIGHTS, D.; MORGAN, G. The concept of strategy in sociology: a note of dissent. Sociology, v.24, n.3, p.475-483, 1990.

Strategic discourse and subjectivity: towards a critical analysis of corporate strategy in organizations. Organization Studies, v. 21, n. 2, p.514-536, 1991.

Organization theory and consumption in a post-modern era. Organization Studies, v.14, n.2, p.211-234, 1993.

KNIGHTS, D.; STURDY, A.; MORGAN, G. The consumer rules? An examination of the rhetoric and "reality" of marketing in financial services. European Journal of Marketing, v.28, n.3, p.42-54, 1994.

; WILLMOTT, H. The hype and hope of interdisciplinary management studies. British Journal of Management, v.8, p.9-22, 1997.

KORTEN, D. When corporations rule the world. San Francisco, CA: Berrett-Koeheler, 2001.

LEVITT, T. The globalization of markets. Harvard Business Review, n.61, p.92-102, May/June 1983.

LOCKE, R. The collapse of the American management mystique. Oxford: Oxford University Press, 1996.

LYSONSKI, S.; DURVASULA, S.; WATSON, J. Should marketing be concerned about attitudes toward marketing and consumerism in New Zealand? A longitudinal study. European Journal of Marketing, v.37, n.4, p.385-406, 2003.

MEYER, J.; ROWAN, B. Institutionalized organizations: formal structure as myth and ceremony. American Journal of Sociology, v.83, n.2, p.340-363, 1977.

MORGAN, G. Marketing discourse and practice: towards a critical analysis. In: ALVESSON, M.; WILLMOTT, H. (Ed.). Critical management studies. London: Sage, 1992.

M OTTA, F.; Maurício Tragtenberg: desvendando ideologias. Revista de Administração de Empresas, v.41, n.3, p.64-68, 2001.

; ALCADIPANI, R.; BRESLER, R. A Valorização do estrangeiro como segregação nas organizações. Revista de Administração Contemporânea, v.5, p.59-79, 2001.

; CALDAS, M. (Ed.). Cultura organizacional e cultura brasileira. São Paulo: Atlas, 1997.

O'SHAUGHNESSY, N. Strategy and US cultural bias. European Journal of Marketing, v.19, n.4, p.23-32, 1985.

OHMAE, K. Managing in a borderless world. Harvard Business Review, May/June, 1989a.

. The global logic of strategic alliances. Harvard Business Review, March/April, 1989b.

Voltando à estratégia. In: MONTGOMERY, C.; PORTER, M. (Org.). Estratégia: a busca da vantagem competitiva. Rio de Janeiro: Campus, 1998.

PAES DE PAULA, A. Tragtenberg e a resistência da crítica: pesquisa e ensino na administração hoje. Revista de Administração de Empresas, v.41, n.3, p.77-81, 2001.

PHILO, G.; MILLER, D. Market killing - what the free market does and what social scientists can do about it. Essex: Pearson Education, 2001.

PIERCY, N. Research in marketing: teasing with trivia or risking relevance?. European Journal of Marketing, v.36, n.3, p.350-363, 2002.

PRAHALAD, C.; HAMEL, G. The core competence of the corporation. Harvard Business Review, May/J une, 1990.

ROCHA, A.; CHRISTENSEN, C. Marketing - teoria e prática no Brasil. 2.ed. São Paulo: Atlas, 1999.

RODRIGUES, S.; CARRIERI, A. A tradição anglo-saxônica nos estudos organizacionais brasileiros. Revista de Administração Contemporânea, n.5, p.81-102, 2001.

SCHENDEL, D.; ANSOFF, I.; CHANNON, D. Statement of editorial policy. Strategic Management Journal, v.1, n.1, p.1-5, 1980.

SHRIVASTAVA, P. Is strategic management ideological? Journal of Management, v.12, n.3, p.363-377, 1986.

SKLAIR, L. Globalization, capitalism \& its alternatives. 3.ed. Oxford: Oxford University, 2002. 
SKLAIR, L. The Sociology of the Global System. $2^{\text {nd }}$ edition, Hemel Hampstead: Harvester Wheatsheaf, 1995.

SMITH, N. Consumer boycotts and consumer sovereignty. European Journal of Marketing, v.21, n.5, p.7-19, 1987.

SPENDER, J.- C. Business policy and strategy as a professional field. In: VOLBERDA, H.; ELFRING, T. (Ed.). Rethinking strategy. London: Sage, 2001.

TENÓRIO, F. Superando a ingenuidade: minha dívida com Guerreiro Ramos. Revista de Administração Pública, v.31, n.5, p.29-44, 1997.

THOM PSON, G. Economic globalization?. In: HELD, D. (ed.) A globalizing world? culture, economics, politics. London: Routledge, 2000.

TIEMSTRA, J. Theories of regulation and the history of consumerism. International Journal of Social Economics, v.19, n.6, p.3-27, 1992.

TRAGTENBERG, M. Administração, poder e ideologia. São Paulo: Moraes, 1980.

WALLERSTEIN, I. The modern world- system. New York: Academic Press, 1974.

WALTERS, P. Research at the "margin" - challenges for scholars working outside the "American- European" domain. International Marketing Review, n.18, p.468-473, 2001.

WHITINGTON, R. 0 que é estratégia. São Paulo: Pioneira, 2001.

WILKIE, W.; MOORE, E. Scholarly research in marketing: exploring the '4 Eras' of thought development. Journal of Public Policy \& Marketing, v.22, n.2, p.116-146, 2003.

YIP, G. Global strategy...in a world of nations? In: BARTLETT, C.; GHOSHAL, S. Texts, cases and readings in cross- border management. 3.ed. New York, NY: M cGraw-Hill. 2000.

ZOU, S.; CAVUSGIL, S. Global strategy: a review and an integrated conceptual framework. European Journal of Marketing, v.30, n.1, p.5269, 1996. 